\title{
Design of bolted side-plated reinforced-concrete beams with partial interaction
}

Ling-Zhi Li BSc(Eng), Phil, PhD, Class 1-RSE (PRC) Assistant Professor, Research Institute of Structural Engineering and Disaster Reduction, College of Civil Engineering, Tongji University, Shanghai, China

\section{Chang-Jiu Jiang BSc(Eng), Phil}

PhD Candidate, Research Institute of Structural Engineering and Disaster Reduction, College of Civil Engineering, Tongji University, Shanghai, China
Ray Kai-Leung Su BSc(Eng), PhD(HK), MHKIE, RPE(STL), CE, MIStructE, Class 1 - RSE (PRC)

Associate Professor, Department of Civil Engineering, The University of Hong Kong, Hong Kong

Sai-Huen Lo BSc(Eng), MPhil, Doc-Ing, SenMIEEE

Professor, Department of Civil Engineering, The University of Hong Kong, Hong Kong

Existing reinforced-concrete $(\mathrm{RC})$ beams can be effectively strengthened by anchoring steel plates to the side faces of the beams using bolts, which is known as the bolted side-plating (BSP) technique. Previous studies have found that the performance of BSP beams is primarily controlled by the degree of partial interaction at the steel-RC interface, which can be conveniently quantified by the strain and curvature factors. In this paper, a new simplified flexural design procedure for BSP beams taking into account partial interaction is presented. Some optimum ranges of strain and curvature factors are first introduced to the flexural design of BSP beams. By ensuring the flexural capacity of a BSP beam is higher than the design moment, the preliminary size of steel plates and the arrangement of bolts can be determined. Following this, the maximum design slips and minimum design strain and curvature factors are calculated and back-checked to ensure the target flexural capacity of the BSP beam has been achieved. An example is presented to illustrate the effectiveness of the optimised design method for BSP beams, considering the effect of partial interaction under realistic loading conditions.

\section{Notation}

$A_{\mathrm{p}} \quad$ cross-section area of the steel plates

$A_{\mathrm{s}} \quad$ cross-section area of the reinforcement

$A_{\text {sc }} \quad$ cross-section area of the compressive reinforcement

$A_{\text {st }} \quad$ cross-section area of the tensile reinforcement

$b \quad$ breadth of the RC beam

$c \quad$ depth of the neutral axis

$D_{\text {c }} \quad$ depth of the RC beam

$D_{\mathrm{p}} \quad$ depth of the steel plates

$D_{\mathrm{sb}} \quad$ depth of the secondary beam

$D_{\text {sl }} \quad$ depth of the floor slab

$d_{\mathrm{b}} \quad$ nominal diameter of the anchor bolts

$d_{\mathrm{tc}} \quad$ lever arm between the tensile reinforcement and the compressive block of the RC beam section

$E_{\mathrm{p}} \quad$ Young's modulus of the steel plates

$E_{\mathrm{s}} \quad$ Young's modulus of the reinforcement

$(E A)_{\mathrm{c}} \quad$ axial stiffness of the unstrengthened RC beam

$(E A)_{\mathrm{p}} \quad$ axial stiffness of the steel plates

$(E I)_{\mathrm{c}}$ flexural stiffness of the unstrengthened RC beam

$(E I)_{\mathrm{p}} \quad$ flexural stiffness of the steel plates

$F, F_{i} \quad$ total external load ( $i$ th point load, $i=1,2,3 \ldots$ )

$F_{\mathrm{p}} \quad$ peak total external load

$F_{\text {p,exp }} \quad$ peak total external load (experimental)

$F_{\mathrm{p} \text {,the }} \quad$ peak total external load (theoretical)

$f_{\mathrm{c}} \quad$ compressive strength of the concrete

$f_{\mathrm{ck}} \quad$ characteristic compressive strength of the concrete

$f_{\mathrm{ub}}$ $f_{\mathrm{y}}$

$f_{\text {yp }}$

$h$

$h_{\mathrm{c}}$

$h_{0}$

$h_{\mathrm{pb}}$

$h_{\mathrm{pt}}$

$I_{\mathrm{p}}$

$i_{\mathrm{c}}$

$i_{\text {cp }}$

$i_{\mathrm{p}}$

$K_{\mathrm{b}}$

$k_{\mathrm{m}}$

L

$L_{\mathrm{s}}$

$M_{\mathrm{d}}$

$M_{\mathrm{G}}$

$M_{\mathrm{Q}}$

$M_{\mathrm{u}}$

$M_{\mathrm{uBSP}}$

$M_{\mathrm{uRC}}$

$M_{\mathrm{uBSP}, \mathrm{FI}}$

$N_{\mathrm{p}}$

$N_{\mathrm{u}}$ yield strength of the reinforcement yield strength of the steel plates

depth of the RC beam

depth of the compressive reinforcement

depth of the tensile reinforcement

depth of the bottom edge of the steel plates

depth of the top edge of the steel plates

second moment of area of the steel plates

effective radius of gyration of the $\mathrm{RC}$ beam

separation between the centroids of the RC beam and the steel plate

effective radius of gyration of the steel plates

shear stiffness of the anchor bolts

stiffness of the connecting media

clear span of the RC beam

shear span

design moment caused by the external loads bending moment caused by the permanent loads bending moment caused by the variable loads flexural strength of the BSP beam flexural strength of the BSP beam flexural strength of the RC beam

flexural strength of the BSP beam under full interaction assumption

tension force of the steel plate resultant axial force of the BSP beam corresponding to $M_{\mathrm{u}}$ 
number of anchor bolts in a shear span parameter including the stiffness components of the BSP beams distributed external transverse load

distributed external transverse load on the steel plates shear force of an anchor bolt

yield shear force of an anchor bolt

shear deformation of the anchor bolts

longitudinal bolt spacing

yield shear deformation of the anchor bolts longitudinal slip on the plate-RC interface transverse slip on the plate-RC interface thickness of one steel plate centroidal level of the steel plates unique value for the strain and the curvature factors modifier in the computation of the bolt shear strength strain factor $\varepsilon_{\mathrm{p}, y_{\mathrm{pc}}} / \varepsilon_{\mathrm{c}, y_{\mathrm{pc}}}$ curvature factor $\varphi_{\mathrm{p}} / \varphi_{\mathrm{c}}$ axial stiffness ratios between the steel plates and the $\mathrm{RC}$ beam ratio between the stiffness of the bolt connection and the flexural stiffness of the RC beam

flexural stiffness ratio between the steel plates and the RC beam partial safety factor for the bolt connection partial safety factor for the concrete material partial safety factor for the actions caused by the permanent loads partial safety factor for the bolt material partial safety factor for the actions caused by the variable loads partial safety factor for the steel material strain of the concrete or the RC beam strain at the peak compressive stress in the concrete ultimate compressive strain of the concrete longitudinal strain of the RC beam strain of the steel plates strain at the bottom edge of the steel plates strain at the top edge of the steel plates longitudinal strain of the steel plates strain of the reinforcement strain of the compressive reinforcement strain of the tensile reinforcement yield strain of the reinforcement yield strain of the steel plate factor defining the effective strength of the concrete factor for the effective depth of the concrete compression zone parameter used to compute the longitudinal slip and the strain factor dimensionless shear transfer ratio at the supports steel ratio of the tensile reinforcement balanced tensile steel ratio stress of the concrete

$\begin{array}{ll}\sigma_{\mathrm{p}} & \text { stress of the steel plates } \\ \sigma_{\mathrm{s}} & \text { stress of the reinforcement } \\ \phi_{\mathrm{c}} & \text { curvature of the RC beam } \\ \phi_{\mathrm{p}} & \text { curvature of the steel plates }\end{array}$

\section{Introduction}

Bolting steel plates to reinforced-concrete (RC) beams has become a widely accepted retrofitting technique over the past several decades due to the minimal additional space occupied and convenience of installation (Li, 2013). Furthermore, bolting steel plates can avoid serious debonding and peeling failures at the ends of the steel plates (Roberts and HajiKazemi, 1989; Souici et al., 2013; Su and Zhu, 2005) when compared with bonding steel plates or fibre-reinforced polymers with adhesive mortar (Adhikary et al., 2000; Buyukozturk et al., 2004; Hamoush and Ahmad, 1990).

Theoretically, steel plates can be bolted to either the soffit or the side faces of RC beams for strengthening purposes. Although attaching steel plates to the beam soffits can effectively increase the flexural strength and stiffness of a beam, it can lead to a substantial decrease in the ductility capacity of the strengthened beam due to over-reinforcement problems (Foley and Buckhouse, 1999; Roberts and Haji-Kazemi, 1989). To preserve the flexural ductility of the strengthened beam, steel plates anchored to the side faces of RC beams, the socalled bolted side-plating (BSP) technique (Hamoush and Ahmad, 1990; Subedi and Baglin, 1998), is preferred. Previous experimental studies (Li et al., 2013; Siu, 2009; Su et al., 2010) have demonstrated that BSP beams possess increased flexural strength without a notable decrease in the ductility capacity.

However, the behaviour of BSP beams is much more complex than that of bolting soffit plating beams, as it is controlled not only by longitudinal but also by transverse slips at the plateRC interface (Johnson and Molenstra, 1991; Oehlers et al., 1997; Siu and $\mathrm{Su}, 2011$ ). Local buckling of side-plated RC beams also needs to be taken into account (Smith et al., 1999a), and the effect of local buckling on the ultimate strength was assessed by a series of experiments (Smith et al., 1999b). A variation on the formulation of the Ritz method using linear combinations of harmonic functions was adopted for the consideration of the plate local buckling coefficients (Smith et al., 2000; Su et al., 2010). Siu and Su (2009) and Su and Siu (2007) developed numerical procedures for predicting the non-linear load-deformation response of bolt groups, and proposed an analytical model by introducing Newmark's model (Newmark et al., 1951) to solve the longitudinal partial interaction of BSP beams under several symmetrical loading conditions (Siu, 2009; Siu and Su, 2010). Su et al. (2014) further extended this analytical model to handle more complicated asymmetrical loading conditions.

Li et al. (2013) and $\mathrm{Su}$ et al. (2013) conducted experimental and numerical studies to investigate the slip of steel plates. The transverse slip was found to be much smaller than the 
longitudinal slip, and was very difficult to measure accurately in the tests. Various assumptions had been made by different researchers on the distribution of the transverse bolt shear, to simplify the complex nature of the transverse slips. By assuming that all shear connectors yielded in the longitudinal direction and that the shear connectors at the mid-span resisted all the vertical loads acting on the side-plate of simply supported BSP beams, Oehlers et al. (1997) related the degree of transverse partial interaction with the elastic stiffness and the number of anchoring bolts utilised. Based on this model, Nguyen et al. (2001) derived a relationship between the longitudinal and transverse partial interactions. Li (2013) proposed a simplified piecewise linear shear transfer model based on the force superposition principle and simplification of shear transfer profiles derived from a previous numerical study ( $\mathrm{Su}$ et al., 2013). The proposed model was capable of predicting transverse shear transfer behaviour during the entire loading process for BSP beams under four-point bending.

Siu and Su (2010) developed a two-alpha approach to analyse the sectional behaviour of BSP beams, in which the degree of partial interaction was measured in the longitudinal and the transverse directions by two indicators, as follows (see Figure 1 for details)

1. $\alpha_{\varepsilon}=\frac{\varepsilon_{\mathrm{p}, y_{\mathrm{pc}}}}{\varepsilon_{\mathrm{c}, y_{\mathrm{pc}}}} \leq 1$

2. $\quad \alpha_{\phi}=\frac{\phi_{\mathrm{p}}}{\phi_{\mathrm{c}}} \leq 1$

where the strain factor $\left(\alpha_{\varepsilon}\right)$ is the ratio between the longitudinal strains of the steel plates and the RC beam $\left(\varepsilon_{\mathrm{p}, y_{\mathrm{pc}}}\right.$ and $\varepsilon_{\mathrm{c}, y_{\mathrm{pc}}}$, respectively) at the centroidal level of the steel plates $\left(y_{\mathrm{pc}}\right)$, and is used to indicate the degree of longitudinal partial interaction caused by the longitudinal slip $\left(S_{\mathrm{lc}}\right)$. The curvature factor $\left(\alpha_{\phi}\right)$ is the ratio between the curvatures of the steel plates and the $\mathrm{RC}$ beam ( $\phi_{\mathrm{p}}$ and $\phi_{\mathrm{c}}$, respectively), and is used to indicate the degree of transverse partial interaction caused by the transverse slip $\left(S_{\mathrm{tr}}\right)$. Lo et al. (2014) conducted a computer simulation to evaluate the performance of BSP beams by indicating the degree of partial interaction in terms of these two factors. The simulation revealed that the influence of the partial interaction on the overall performance was significant, and $90 \%$ of the full strengthening capacity was already achieved when the strain or the curvature factor was chosen to be no less than $0 \cdot 6$. This proposed value for the two factors is of great importance in simplifying the design procedure of BSP beams.

The aforementioned research findings demonstrate that the behaviour of BSP beams is very different from that of conventional RC beams and bonded side-plated RC beams. Hence, the traditional analysis and design methods of conventional $\mathrm{RC}$ beams are not applicable to BSP beams. In light of this

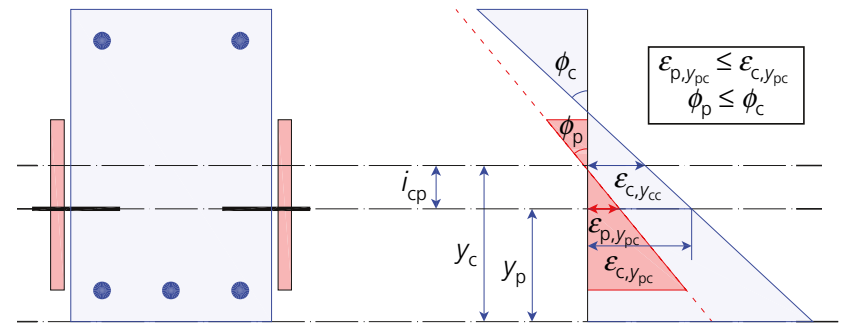

(a)

(b)

Figure 1. Strain profile of a BSP section with partial interaction: (a) section; (b) strain profile

situation, a new design procedure is proposed in this paper. First, the design formulas used to compute the flexural strength of conventional RC beams are modified by introducing the recommended optimum strain and curvature factors proposed by the authors (Lo et al., 2014), to take into account the partial interactions in both the longitudinal and transverse directions. Second, design equations are derived for estimating the dimensions of steel plates and the bolt arrangements. Finally, the maximum plate-RC slips and the minimum strain and curvature factors are back-checked ( $\mathrm{Li}, 2013)$, to ensure that those factors and slips are within the recommended design limits. A worked example is given to illustrate the strengthening design of both lightly and moderately reinforced RC beams subjected to various loading arrangements.

\section{Design model}

\subsection{Assumptions}

When computing the ultimate moment resistance of a BSP beam section, the following assumptions are employed.

- The bond-slip effect of both tensile and compressive reinforcement is ignored; that is, the strain in the reinforcing bars is the same as that in the surrounding concrete.

- The cross-sections of both the steel plates and the RC beam remain in plane after deformation.

- The tensile strength of concrete is ignored; the compressive stress of concrete, and the tensile and compressive stresses in reinforcing steel and plate steel are derived from the design stress-strain relations given in the Eurocodes (BSI, 2004).

- The shear strength of anchor bolts can be computed according to the Eurocodes (BSI, 2005).

\subsection{Material models}

The stress-strain relation for the design of concrete material in the Eurocodes (BSI, 2004) is adopted, as shown in Figure 2.

3. $\sigma_{\mathrm{c}}=\left\{\begin{array}{lc}f_{\mathrm{c}}\left[1-\left(1-\frac{\varepsilon_{\mathrm{c}}}{\varepsilon_{\mathrm{c} 0}}\right)^{2}\right] & 0 \leq \varepsilon_{\mathrm{c}} \leq \varepsilon_{\mathrm{c} 0} \\ f_{\mathrm{c}} & \varepsilon_{\mathrm{c} 0} \leq \varepsilon_{\mathrm{c}} \leq \varepsilon_{\mathrm{cu}}\end{array}\right.$ 


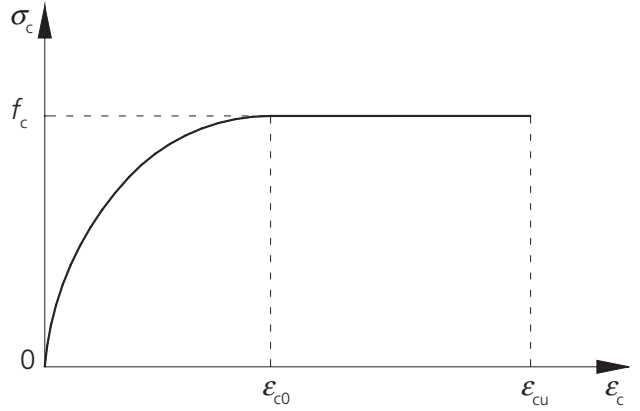

Figure 2. Stress-strain curve of concrete in the compression condition

where $\sigma_{\mathrm{c}}$ is the stress at strain $\varepsilon_{\mathrm{c}}, \varepsilon_{\mathrm{c} 0}$ is the strain at the maximum strength $f_{\mathrm{c}}$ and $\varepsilon_{\mathrm{cu}}$ is the ultimate strain.

Both the reinforcement and steel plates are considered as elasto-plastic materials (BSI, 2004), as shown in Figure 3.

4. $\sigma_{\mathrm{s}}=\left\{\begin{array}{ll}E_{\mathrm{s}} \varepsilon_{\mathrm{s}} & \left|\varepsilon_{\mathrm{s}}\right|<\varepsilon_{\mathrm{y}} \\ f_{\mathrm{y}} & \left|\varepsilon_{\mathrm{s}}\right|<\varepsilon_{\mathrm{y}}\end{array} \quad\right.$ where $\quad E_{\mathrm{s}}=f_{\mathrm{y}} / \varepsilon_{\mathrm{y}}$

5. $\quad \sigma_{\mathrm{p}}=\left\{\begin{array}{ll}E_{\mathrm{p}} \varepsilon_{\mathrm{p}} & \left|\varepsilon_{\mathrm{p}}\right|<\varepsilon_{\mathrm{yp}} \\ f_{\mathrm{yp}} & \left|\varepsilon_{\mathrm{p}}\right|<\varepsilon_{\mathrm{yp}}\end{array} \quad\right.$ where $\quad E_{\mathrm{p}}=f_{\mathrm{yp}} / \varepsilon_{\mathrm{yp}}$

As the failure of anchor bolts in shear is associated predominantly with limited ductility, a simple elastic shear forceslip relation is adopted for anchor bolts, as shown in Figure 4, and whose maximum slip in BSP beams should always be less than $S_{\text {by }}$

6. $R_{\mathrm{b}}=K_{\mathrm{b}} S \quad S \leq S_{\mathrm{by}} \quad$ where $\left\{\begin{array}{l}K_{\mathrm{b}}=R_{\mathrm{by}} / S_{\mathrm{by}} \\ R_{\mathrm{by}}=\alpha_{\mathrm{v}} f_{\mathrm{ub}} \frac{\pi d_{\mathrm{b}}^{2}}{4}\end{array}\right.$

where $f_{\mathrm{ub}}$ and $d_{\mathrm{b}}$ are the ultimate tensile strength and the nominal diameter of the anchor bolts, respectively, and $\alpha_{\mathrm{v}}$ is a modifier with a value of 0.5 or 0.6 chosen in accordance with the Eurocodes (BSI, 2005).

\subsection{Sectional analysis and flexural strength}

It has been found (Lo et al., 2014) that $90 \%$ of the full strengthening capacity can be achieved when the strain or the curvature factor is chosen to be not less than $0 \cdot 6$. Therefore, for brevity, a unique value $(\alpha=0 \cdot 6)$ is chosen for both $\alpha_{\varepsilon}$ and $\alpha_{\phi}$.

7. $\alpha_{\varepsilon}=\alpha_{\phi}=\alpha=0.6$

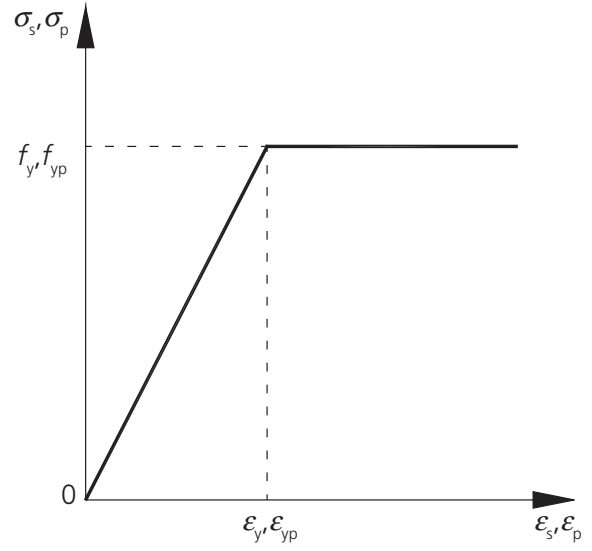

Figure 3. Stress-strain curve of the steel reinforcement and steel plates

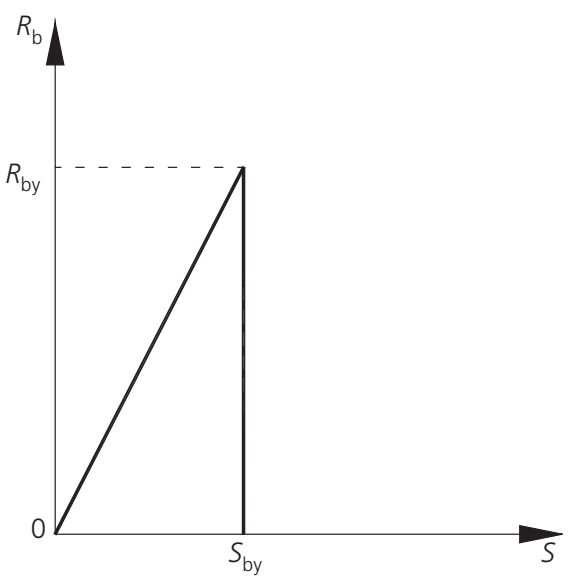

Figure 4. Shear force-slip curve of the anchor bolts

Thus, the cross-sectional strain profile of the BSP beam in Figure 1(b) can be simplified, as illustrated in Figure 5(b). In order to obtain the flexural strength, the cross-sectional stress profile at the ultimate limit state is also illustrated in Figure 5(c). The concrete strain at the compressive surface reaches the ultimate strain $\varepsilon_{\mathrm{cu}}$, and therefore the curvature of the RC beam can be expressed by the depth of the neutral axis $(c)$ as

$$
\text { 8. } \phi_{\mathrm{c}}=\frac{\varepsilon_{\mathrm{cu}}}{c}
$$

The strains of the compressive and tensile reinforcement can be written in terms of their depths $\left(h_{\mathrm{c}}\right.$ and $\left.h_{0}\right)$ as follows.

9. $\varepsilon_{\mathrm{sc}}=\phi_{\mathrm{c}}\left(c-h_{\mathrm{c}}\right)$

10. $\varepsilon_{\mathrm{st}}=\phi_{\mathrm{c}}\left(h_{0}-c\right)$ 


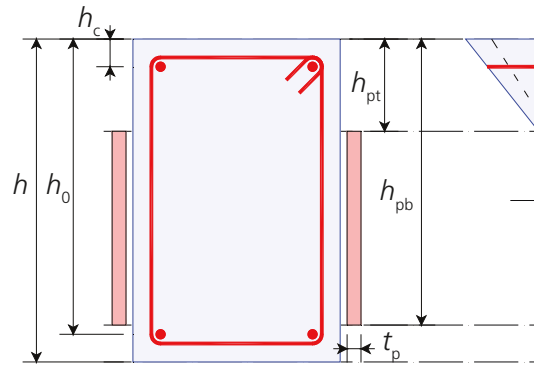

(a)

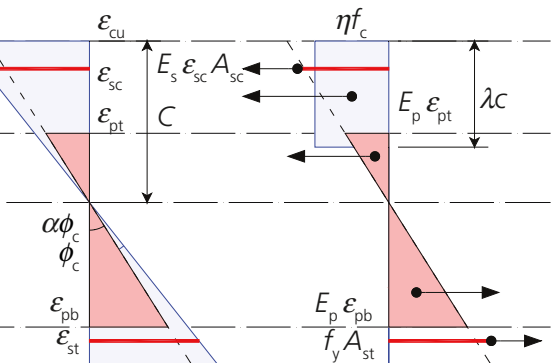

(b) (c)

Figure 5. Sectional strain and stress profiles in a BSP beam:

(a) section; (b) strain profile; (c) stress profile

The strains of the steel plates at their top and bottom edges are

$$
\text { 11. } \varepsilon_{\mathrm{pt}}=\alpha \phi_{\mathrm{c}}\left(c-h_{\mathrm{pt}}\right)
$$

12. $\varepsilon_{\mathrm{pb}}=\alpha \phi_{\mathrm{c}}\left(h_{\mathrm{pb}}-c\right)$

For a satisfactory strengthening design, the outermost layer of the tensile reinforcement should yield before concrete crushing occurs; thus, its tensile stress is the yield strength $f_{\mathrm{y}}$ at the ultimate limit state. By substituting the strains in Equations 9-12 into the material constitutive relations, the internal sectional axial force $N_{\mathrm{u}}$ and bending moment $M_{\mathrm{u}}$ can be obtained. Furthermore, the pure bending condition should be satisfied as

13.

$$
\begin{aligned}
N_{\mathrm{u}}= & \eta f_{\mathrm{c}} b \lambda c+E_{\mathrm{s}} A_{\mathrm{sc}} \frac{\varepsilon_{\mathrm{cu}}}{c}\left(c-h_{\mathrm{c}}\right) \\
& -f_{\mathrm{y}} A_{\mathrm{st}}+E_{\mathrm{p}} t_{\mathrm{p}} \frac{\alpha \varepsilon_{\mathrm{cu}}}{c}\left(c-h_{\mathrm{pt}}\right)^{2} \\
& -E_{\mathrm{p}} t_{\mathrm{p}} \frac{\alpha \varepsilon_{\mathrm{cu}}}{c}\left(h_{\mathrm{pb}}-c\right)^{2}=0
\end{aligned}
$$

where $\mathrm{b}$ is the breadth of the RC beam, $\lambda$ is a factor defining the effective depth of the concrete compression zone and $\eta$ is a factor defining the effective strength, as shown in Figure 5(c); values of 0.8 and 1.0 are adopted for $\lambda$ and $\eta$, respectively, if the concrete grade is lower than C50 according to the Eurocodes (BSI, 2004).

It can be seen that $c$ is the only unknown in Equation 13; a solution of this quadratic equation to yield the neutral axis depth $c$ is attainable as

$$
c=\frac{\sqrt{B^{2}-4 A C}-B}{2 A}
$$

14.

$$
\text { where }\left\{\begin{array}{l}
A=\eta f_{\mathrm{c}} b \lambda \\
B=E_{\mathrm{s}} A_{\mathrm{sc}} \varepsilon_{\mathrm{cu}}-f_{\mathrm{y}} A_{\mathrm{st}}+2 E_{\mathrm{p}} t_{\mathrm{p}} \alpha \varepsilon_{\mathrm{cu}}\left(h_{\mathrm{pb}}-h_{\mathrm{pt}}\right) \\
C=-\left[E_{\mathrm{s}} A_{\mathrm{sc}} \varepsilon_{\mathrm{cu}} h_{\mathrm{c}}+E_{\mathrm{p}} t_{\mathrm{p}} \alpha \varepsilon_{\mathrm{cu}}\left(h_{\mathrm{pb}}^{2}-h_{\mathrm{pt}}^{2}\right)\right]
\end{array}\right.
$$

Then, the ultimate moment resistance $\left(M_{\mathrm{u}}\right)$ can be expressed as

$$
\begin{aligned}
M_{\mathrm{u}}= & \eta f_{\mathrm{c}} b \lambda c^{2}\left(1-\frac{\lambda}{2}\right)+E_{\mathrm{s}} A_{\mathrm{sc}} \frac{\varepsilon_{\mathrm{cu}}}{c}\left(c-h_{\mathrm{c}}\right)^{2}+f_{\mathrm{y}} A_{\mathrm{st}}\left(h_{0}-c\right) \\
& +\frac{2}{3} E_{\mathrm{p}} t_{\mathrm{p}} \frac{\alpha \varepsilon_{\mathrm{cu}}}{c}\left(c-h_{\mathrm{pt}}\right)^{3}+\frac{2}{3} E_{\mathrm{p}} t_{\mathrm{p}} \frac{\alpha \varepsilon_{\mathrm{cu}}}{c}\left(h_{\mathrm{pb}}-c\right)^{3}
\end{aligned}
$$

After obtaining the neutral axis depth (c) from Equation 13, it should be substituted into Equations 8-12, to check if the strains of the reinforcement and the steel plates $\left(\varepsilon_{\mathrm{sc}}, \varepsilon_{\mathrm{pt}}\right.$ and $\left.\varepsilon_{\mathrm{pb}}\right)$ surpass their corresponding yield strains $\left(\varepsilon_{\mathrm{y}}\right.$ and $\left.\varepsilon_{\mathrm{yp}}\right)$ or change their directions, as follows.

- If yielding of the compressive reinforcement occurs $\left(\varepsilon_{\mathrm{sc}}>\varepsilon_{\mathrm{y}}\right)$, the stress in Equations 13 and 15 should be replaced with $f_{\mathrm{y}}$.

- If yielding of the top or bottom edge of the steel plates occurs $\left(\varepsilon_{\mathrm{pt}}>\varepsilon_{\mathrm{yp}}\right.$ or $\left.\varepsilon_{\mathrm{pb}}>\varepsilon_{\mathrm{yp}}\right)$, the corresponding triangular stress block in Figure 5(c) should be replaced with a trapezoidal stress block, as shown in Figure 6(a), and Equations 13 and 15 should be changed accordingly.

- If the strain on the top edge of the steel plates is negative $\left(\varepsilon_{\mathrm{pt}}<0\right)$, this means the steel plates are in tension along the entire section, as shown in Figure 6(b). Actually, this phenomenon implies that the steel plates are shallow and are attached to the tensile region of the $\mathrm{RC}$ beam. In this case, no modification is needed for Equations 13 and 15.

\subsection{Verification by experimental results}

For a BSP beam subjected to four-point bending, the peak load can be expressed conveniently as $F_{\mathrm{p}}=2 M_{\mathrm{u}} / L_{\mathrm{s}}$ (where $L_{\mathrm{s}}$ is the shear span). The results extracted from a previous experimental study ( $\mathrm{Li}$ et al., 2013) were employed to verify the aforementioned sectional analysis method, as shown in Table 1. It is evident that the proposed sectional analysis method can predict the peak load of the specimens with a satisfactory mean discrepancy of approximately $5 \cdot 2 \%$. 


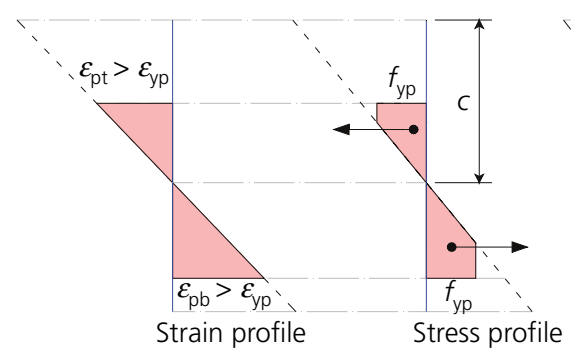

(a)

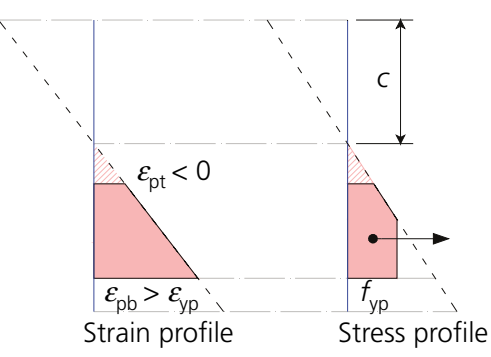

(b)

Figure 6. Sectional strain and stress profiles of steel plates in a BSP beam at the occurrence of (a) plate yielding and (b) plate entire-sectional tension

\begin{tabular}{lccc}
\hline Specimen & $F_{\mathrm{p}, \text { exp }}$ & $F_{\mathrm{p}, \text { the }}$ & $\left|F_{\mathrm{p}, \text { the }}-F_{\mathrm{p}, \text { exp }}\right| F_{\mathrm{p}, \text { exp }}: \%$ \\
\hline CONTROL & 268 & 278 & $3 \cdot 7$ \\
P100B300 & 317 & 335 & $5 \cdot 7$ \\
P100B450 & 327 & 364 & $11 \cdot 3$ \\
P250B300R & 382 & 369 & $3 \cdot 4$ \\
P250B450R & 377 & 375 & $0 \cdot 5$
\end{tabular}

Mean absolute error

Table 1. Comparison of experimental and theoretical peak loads

\section{Proposed design procedure}

\subsection{Estimation of plate sizing}

In the BSP strengthening design for a specific RC beam, the geometry of the RC beam and the loading arrangement are known; thus, the required design bending moment $\left(M_{\mathrm{d}}\right)$ is

16. $M_{\mathrm{d}}=\gamma_{\mathrm{G}} M_{\mathrm{G}}+\gamma_{\mathrm{Q}} M_{\mathrm{Q}}+\ldots$

where $M_{\mathrm{G}}, M_{\mathrm{Q}}, \gamma_{\mathrm{G}}$ and $\gamma_{\mathrm{Q}}$ are the bending moment actions caused by the permanent and variable loads and their corresponding partial factors, as specified in the design codes (BSI, 2004).

As the layout and dimensions of the existing $\mathrm{RC}$ beams are known, the available depth and position of the side-bolted steel plates can be determined, which means that the top-edge depth $\left(h_{\mathrm{pt}}\right)$ of the steel plates (as shown in Figure 5) should be greater than the depths of the existing slab $\left(D_{\mathrm{sl}}\right)$ and the secondary beams $\left(D_{\mathrm{sb}}\right)$, and the bottom-edge depth $\left(h_{\mathrm{pb}}\right)$ should be less than the depth of the RC beam $\left(D_{\mathrm{c}}\right)$. If any other restraints, such as ceiling installation fitments and beam-crossing pipes, exist, the depth of the steel plates may be more limited. Once the depth of the steel plates is chosen, several available thicknesses of the steel plates $\left(2 t_{\mathrm{p}}\right)$ can be chosen, and the design flexural strength of the BSP beam $\left(M_{\mathrm{u}}\right)$ can be computed by using Equations 13 and 15, with safety factors as follows.

In most cases of a real strengthening design of BSP beams, yielding occurs at the compressive reinforcement and the bottom edge of steel plates but not on the top edge of the steel plates (i.e. $\varepsilon_{\mathrm{sc}}>\varepsilon_{\mathrm{y}}, \varepsilon_{\mathrm{pb}}>\varepsilon_{\mathrm{yp}}$ and $\varepsilon_{\mathrm{pt}}<\varepsilon_{\mathrm{yp}}$ ); thus, the design flexural strength $\left(M_{\mathrm{u}}\right)$ can be determined as

$$
\begin{aligned}
M_{\mathrm{u}}= & \frac{1}{\gamma_{\mathrm{c}}} \eta f_{\mathrm{c}} b \lambda c^{2}\left(1-\frac{\lambda}{2}\right)+\frac{1}{\gamma_{\mathrm{s}}}\left[E_{\mathrm{s}} A_{\mathrm{sc}} \frac{\varepsilon_{\mathrm{cu}}}{c}\left(c-h_{\mathrm{c}}\right)^{2}\right. \\
& \left.+f_{\mathrm{y}} A_{\mathrm{st}}\left(h_{0}-c\right)\right]+\frac{1}{\gamma_{\mathrm{c}}}\left\{\frac{2}{3} E_{\mathrm{p}} t_{\mathrm{p}} \frac{\alpha \varepsilon_{\mathrm{cu}}}{c}\left(c-h_{\mathrm{pt}}\right)^{3}\right. \\
& \left.+f_{\mathrm{yp}} t_{\mathrm{p}}\left[\left(h_{\mathrm{pb}}-c\right)^{2}-\frac{1}{3}\left(\frac{c \varepsilon_{\mathrm{yp}}}{\alpha \varepsilon_{\mathrm{cu}}}\right)^{2}\right]\right\}
\end{aligned}
$$$$
17 .
$$$$
\text { 18. where }\left\{\begin{aligned}
c & =\frac{\sqrt{B^{2}-4 A C}-B}{2 A} \\
A & =\frac{1}{\gamma_{\mathrm{c}}} \eta f_{\mathrm{c}} b \lambda+\frac{1}{\gamma_{\mathrm{s}}}\left[E_{\mathrm{p}} t_{\mathrm{p}} \alpha \varepsilon_{\mathrm{cu}}+f_{\mathrm{yp}} t_{\mathrm{p}}\left(2+\frac{\varepsilon_{\mathrm{yp}}}{\alpha \varepsilon_{\mathrm{cu}}}\right)\right] \\
B & =\frac{1}{\gamma_{\mathrm{s}}}\left[f_{\mathrm{y}}\left(A_{\mathrm{sc}}-A_{\mathrm{st}}\right)-2 t_{\mathrm{p}}\left(f_{\mathrm{yp}} h_{\mathrm{pb}}+E_{\mathrm{p}} \alpha \varepsilon_{\mathrm{cu}} h_{\mathrm{pt}}\right)\right] \\
C & =\frac{1}{\gamma_{\mathrm{s}}} E_{\mathrm{p}} t_{\mathrm{p}} \alpha \varepsilon_{\mathrm{cu}} h_{\mathrm{pt}}^{2}
\end{aligned}\right.
$$

where the coefficients $\gamma_{\mathrm{c}}$ and $\gamma_{\mathrm{s}}$ are the partial factors for the concrete and steel material, respectively.

- In some cases, yielding also occurs at the top edge of the steel plates (i.e. $\varepsilon_{\mathrm{pt}}>\varepsilon_{\mathrm{yp}}$ ), and thus the design flexural strength $\left(M_{\mathrm{u}}\right)$ can be determined as

$$
\begin{aligned}
M_{\mathrm{u}}= & \frac{1}{\gamma_{\mathrm{c}}} \eta f_{\mathrm{c}} b \lambda c^{2}\left(1-\frac{\lambda}{2}\right)+\frac{1}{\gamma_{\mathrm{s}}}\left[E_{\mathrm{s}} A_{\mathrm{sc}} \frac{\varepsilon_{\mathrm{cu}}}{c}\left(c-h_{\mathrm{c}}\right)^{2}\right. \\
& \left.+f_{\mathrm{y}} A_{\mathrm{st}}\left(h_{0}-c\right)\right]+\frac{1}{\gamma_{\mathrm{s}}} f_{\mathrm{yp}} t_{\mathrm{p}}\left[\left(c-h_{\mathrm{pt}}\right)^{2}+\left(h_{\mathrm{pb}}-c\right)^{2}\right. \\
& \left.-\frac{2}{3}\left(\frac{c \varepsilon_{\mathrm{yp}}}{\alpha \varepsilon_{\mathrm{cu}}}\right)^{2}\right]
\end{aligned}
$$$$
19 .
$$ 
20. where $\left\{\begin{aligned} c & =\frac{B}{A} \\ A & =\frac{1}{\gamma_{\mathrm{c}}} \eta f_{\mathrm{c}} b \lambda+\frac{1}{\gamma_{\mathrm{s}}} 4 f_{\mathrm{yp}} t_{\mathrm{p}} \\ B & =\frac{1}{\gamma_{\mathrm{s}}}\left[2 f_{\mathrm{yp}} t_{\mathrm{p}}\left(h_{\mathrm{pb}}+h_{\mathrm{pt}}\right)+f_{\mathrm{y}}\left(A_{\mathrm{st}}-A_{\mathrm{sc}}\right)\right]\end{aligned}\right.$

It is noted that in the simplified design procedure both the target strain and curvature factors may be taken as $\alpha=0.6$ in Equations 17-20. A trial-and-error procedure might be needed to determine the plate thickness $\left(2 t_{\mathrm{p}}\right)$ by implementing the prerequisite that the design flexural strength $\left(M_{\mathrm{u}}\right)$ should be greater than the bending moment $\left(M_{\mathrm{d}}\right)$ caused by external loads; that is

\section{1. $M_{\mathrm{u}} \geq M_{\mathrm{d}}$}

After evaluating the limitation of the size of steel plates, the thickness and depth (i.e. $2 t_{\mathrm{p}}$ and $D_{\mathrm{p}}$ ) of the steel plates can be chosen from the practical and available inventory. The type $\left(f_{\mathrm{yp}}\right.$ and $\left.E_{\mathrm{p}}\right)$ and locations $\left(h_{\mathrm{pb}}\right.$ and $\left.h_{\mathrm{pt}}\right)$ of the steel plates can be defined.

\subsection{Estimation of the number of bolts}

To ensure the occurrence of ductile axial yielding of plates prior to the brittle shear failure of bolts, the number of anchor bolts $\left(n_{\mathrm{b}}\right)$ can be estimated by the inequality

22.

$$
\frac{1}{4} n_{\mathrm{b}} \frac{R_{\mathrm{by}}}{\gamma_{\mathrm{M} 2}} \geq \gamma_{\mathrm{b}} \frac{f_{\mathrm{yp}}\left(h_{\mathrm{pb}}-h_{\mathrm{pt}}\right) t_{\mathrm{p}}}{\gamma_{\mathrm{s}}}
$$

where $R_{\mathrm{by}}$ is the yield shear force of an anchor bolt (see Equation 6); $\gamma_{\mathrm{M} 2}$ is the partial safety factor for bolts, with a value of 1.25 recommended by the Eurocodes (BSI, 2005); and $\gamma_{\mathrm{b}}$ is a coefficient that takes into account the varying distribution of bolt shear force along the beam span. A value for $\gamma_{\mathrm{b}}$ from 1.5 to 2.0 can be chosen, because the shear transfer profiles are between triangular and parabolic, as shown in the literature ( $\mathrm{Li}, 2013)$. The leading constant $1 / 4$ on the left-hand side of the equation is adopted as there are two steel plates and two shear spans for each plate in a BSP beam.

When the minimum number of anchor bolts is determined, the actual plate-bolt layout can be adjusted to correspond to the practical plate size and minimum bolt spacing specified in the design codes (BSI, 2005). Then, the preliminary strengthening scheme can be determined. Of course, the partial interaction of BSP beams is highly dependent not only on the beam geometries but also on the load arrangement, and, thus, should be verified according to each specific case.

\subsection{Verification of the partial interaction}

The partial interaction, which is caused by the longitudinal and transverse slips between the steel plates and the RC beams, should be checked in terms of the maximum longitudinal and transverse slips $\left(S_{\mathrm{lc} \text {, max }}\right.$ and $\left.S_{\mathrm{tr} \text {,max }}\right)$, and the minimum strain and curvature factors $\left(\alpha_{\varepsilon, \min }\right.$ and $\left.\alpha_{\phi, \min }\right)$, as follows.

23

$$
\sqrt{S_{\mathrm{lc}, \max }^{2}+S_{\mathrm{tr}, \max }^{2}} \leq S_{\mathrm{by}}
$$

24. $\min \left(\alpha_{\varepsilon, \min }, \alpha_{\phi, \min }\right) \geq \alpha=0 \cdot 6$

The expressions for $S_{\mathrm{lc} \text { max }}, S_{\mathrm{tr}, \max }, \alpha_{\varepsilon, \min }$ and $\alpha_{\phi, \text { min }}$ are mainly controlled by the depth of the steel plates used in BSP beams (Li, 2013). The steel plates in a BSP beam retrofit the RC beam by both their flexural stiffness $\phi_{\mathrm{p}}(E I)_{\mathrm{p}}$ and the additional eccentric-compression-force effect $i_{\mathrm{cp}} N_{\mathrm{p}}$. The proportions of these two effects can be identified by the modulus ratio $I_{\mathrm{p}}$ : $A_{\mathrm{p}} i_{\mathrm{cp}}^{2}$, which is the ratio between the second moment of the area of the steel plates with regard to the plate centroid $\left(I_{\mathrm{p}}\right)$ and the RC centroid $\left(A_{\mathrm{p}} i_{\mathrm{cp}}^{2}\right)$, as shown in Figure 7.

25.

$$
I_{\mathrm{p}}: A_{\mathrm{p}} i_{\mathrm{cp}}^{2}\left\{\begin{array}{l}
\frac{2 t_{\mathrm{p}}}{12}\left(\frac{D_{\mathrm{c}}}{3}\right)^{3}: 2 t_{\mathrm{p}} \frac{D_{\mathrm{c}}}{3}\left(\frac{D_{\mathrm{c}}}{3}\right)^{2}=\frac{1}{12} \quad \frac{D_{\mathrm{p}}}{D_{\mathrm{c}}}<\frac{1}{3} \\
>\frac{2 t_{\mathrm{p}}}{12}\left(\frac{D_{\mathrm{c}}}{2}\right)^{3}: 2 t_{\mathrm{p}} \frac{D_{\mathrm{c}}}{2}\left(\frac{D_{\mathrm{c}}}{4}\right)^{2}=\frac{1}{3} \quad \frac{D_{\mathrm{p}}}{D_{\mathrm{c}}}>\frac{1}{2}
\end{array}\right.
$$

For shallow steel plates with a depth $D_{\mathrm{p}} / D_{\mathrm{c}}<1 / 3$, the modulus ratio $I_{\mathrm{p}}: A_{\mathrm{p}} i_{\mathrm{cp}}^{2}$ is less than $1 / 12$; thus, the error caused by neglecting the flexural stiffness $(E I)_{\mathrm{p}}$ and treating the plates as additional tensile reinforcement bars might be acceptable. However, for deep steel plates with a depth $D_{\mathrm{p}} / D_{\mathrm{c}}>1 / 2$, the modulus ratio $I_{\mathrm{p}}: A_{\mathrm{p}} i_{\mathrm{cp}}^{2}$ is greater than $1 / 3$; thus, their flexural stiffness can no longer be ignored.

For a BSP beam under four-point bending, the maximum longitudinal and transverse slips occur at the plate end, the minimum strain factor occurs at the loading point and the minimum curvature factor occurs at the midspan. Their magnitudes are given by the expressions $(\mathrm{Li}, 2013)$

26. $\left.S_{\mathrm{lc}, \max }\right|_{x=0}=\frac{F i_{\mathrm{cp}}}{p^{2}\left[(E I)_{\mathrm{c}}+(E I)_{\mathrm{p}}\right]}\left[1-\frac{1}{2 \cos h(p L / 3)-1}\right]$

$$
\begin{aligned}
& \left.S_{\text {tr } \max }\right|_{x=0} \\
& =\left\{\begin{array}{cl}
\frac{F L^{3}}{(E I)_{\mathrm{c}}\left[0.032 L^{4} \beta_{\mathrm{m}}\left(1+\beta_{\mathrm{p}}^{-1}\right)-44 \cdot 4\right]} & \frac{D_{\mathrm{p}}}{D_{\mathrm{c}}}<\frac{1}{3} \\
\frac{F L^{3}}{(E I)_{\mathrm{c}}\left[0.025 L^{4} \beta_{\mathrm{m}}\left(1+\beta_{\mathrm{p}}^{-1}\right)-44 \cdot 4\right]} & \frac{D_{\mathrm{p}}}{D_{\mathrm{c}}}>\frac{1}{2}
\end{array}\right.
\end{aligned}
$$$$
27 .
$$ 


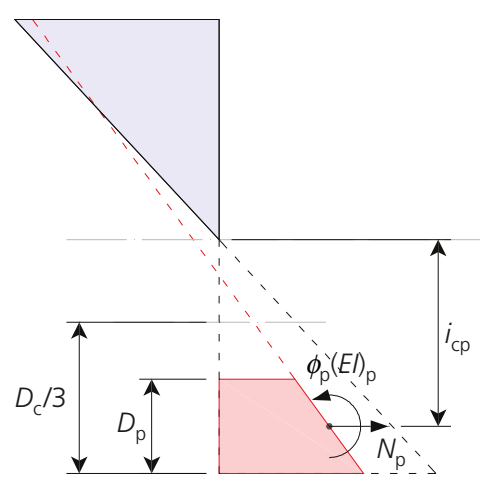

(a)

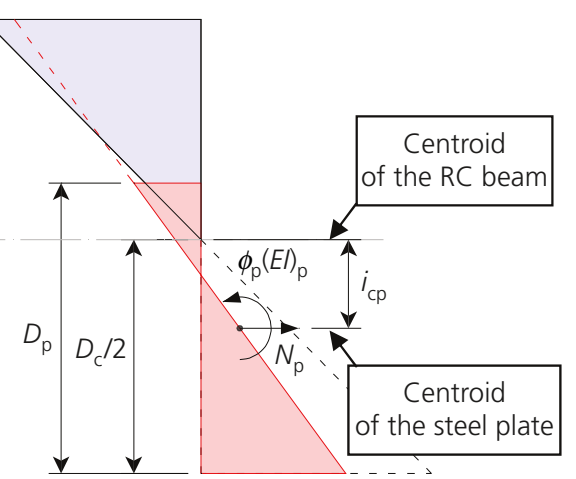

(b)

Figure 7. Definition of (a) shallow and (b) deep steel plates

28.

$\left.\alpha_{\varepsilon, \min }\right|_{x=L / 3}$

$$
=\left(1+\frac{(E A)_{\mathrm{p}} / k_{\mathrm{m}}}{\{L[\cos h(p L / 3)-1] / 3 p \sin h(p L / 3)\}-\left(1 / p^{2}\right)}\right)^{-1}
$$

$\left.\alpha_{\phi, \min }\right|_{x=L / 2}$

29.

$$
= \begin{cases}\left(1 \cdot 8+0 \cdot 8 \beta_{\mathrm{p}}-2500 \beta_{\mathrm{p}} L^{-4} \beta_{\mathrm{m}}^{-1}\right)^{-1} & \frac{D_{\mathrm{p}}}{D_{\mathrm{c}}}<\frac{1}{3} \\ \left(3 \cdot 6+2 \cdot 7 \beta_{\mathrm{p}}-6500 \beta_{\mathrm{p}} L^{-4} \beta_{\mathrm{m}}^{-1}\right)^{-1} & \frac{D_{\mathrm{p}}}{D_{\mathrm{c}}}>\frac{1}{2}\end{cases}
$$

For a BSP beam under a uniformly distributed load, the maximum longitudinal and transverse slips occur at the plate end, and the minimum strain and curvature factors occur at the midspan. Their magnitudes are given by the expressions (Li, 2013)

30. $\left.S_{\mathrm{lc}, \max }\right|_{x=0}=\frac{q i_{\mathrm{cp}}}{p^{3}\left[(E I)_{\mathrm{c}}+(E I)_{\mathrm{p}}\right]}\left[\frac{p L}{2}-\tan h\left(\frac{p L}{2}\right)\right]$

31. $\left.S_{\mathrm{tr}, \max }\right|_{x=0}=\frac{\xi_{\mathrm{S}}}{L^{4} \beta_{\mathrm{m}}} \frac{q L^{4}}{(E I)_{\mathrm{c}}}$

32. $\left.\alpha_{\varepsilon, \min }\right|_{x=L / 2}=\left(1+\frac{(E A)_{\mathrm{p}} / k_{\mathrm{m}}}{\left\{L^{2} / 8[1-\sec h(p L / 2)]\right\}-\left(1 / p^{2}\right)}\right)^{-1}$

$\left.\alpha_{\phi, \min }\right|_{x=L / 2}$

33. $= \begin{cases}0.72 L^{4} \beta_{\mathrm{m}}\left[5400 \beta_{\mathrm{p}}+L^{4} \beta_{\mathrm{m}}\left(\beta_{\mathrm{p}}+1\right)\right] / D & \frac{D_{\mathrm{p}}}{D_{\mathrm{c}}}<\frac{1}{3} \\ 0.63 L^{4} \beta_{\mathrm{m}}\left[10300 \beta_{\mathrm{p}}+L^{4} \beta_{\mathrm{m}}\left(\beta_{\mathrm{p}}+1\right)\right] / D & \frac{D_{\mathrm{p}}}{D_{\mathrm{c}}}>\frac{1}{2}\end{cases}$
34. $\quad \xi_{\mathrm{S}}= \begin{cases}20 L^{4} \beta_{\mathrm{m}} \beta_{\mathrm{p}}\left[29300 \beta_{\mathrm{p}}+L^{4} \beta_{\mathrm{m}}\left(\beta_{\mathrm{p}}+1\right)\right] / C & \frac{D_{\mathrm{p}}}{D_{\mathrm{c}}}<\frac{1}{3} \\ 25 L^{4} \beta_{\mathrm{m}} \beta_{\mathrm{p}}\left[21100 \beta_{\mathrm{p}}+L^{4} \beta_{\mathrm{m}}\left(\beta_{\mathrm{p}}+1\right)\right] / C & \frac{D_{\mathrm{p}}}{D_{\mathrm{c}}}>\frac{1}{2}\end{cases}$

35. $C=\left\{\begin{array}{c}L^{8} \beta_{\mathrm{m}}^{2}\left(\beta_{\mathrm{p}}+1\right)^{2}+28200 \beta_{\mathrm{p}}\left[L^{4} \beta_{\mathrm{m}}(\beta+1)-5500 \beta_{\mathrm{p}}\right] \\ \frac{D_{\mathrm{p}}}{D_{\mathrm{c}}}<\frac{1}{3} \\ L^{8} \beta_{\mathrm{m}}^{2}\left(\beta_{\mathrm{p}}+1\right)^{2}+16900 \beta_{\mathrm{p}}\left[L^{4} \beta_{\mathrm{m}}(\beta+1)-7200 \beta_{\mathrm{p}}\right] \\ \frac{D_{\mathrm{p}}}{D_{\mathrm{c}}}>\frac{1}{2}\end{array}\right.$

\subsection{General strengthening strategies and preliminary design}

The flexural strength of an RC beam can be simply expressed as $M=\left(f_{\mathrm{y}} / \gamma_{\mathrm{s}}\right) A_{\mathrm{st}} d_{\mathrm{tc}}$, where $d_{\mathrm{tc}}$ is the lever arm controlled by the depth of the beam $(h)$. Therefore, the flexural strength of an $\mathrm{RC}$ beam can be enhanced by increasing either the strength of tensile reinforcement $\left(f_{\mathrm{y}} A_{\mathrm{st}}\right)$ or the depth of the beam $(h)$. In the structural design, either of these two measures can be used, but the measures are highly controlled by the position of each $\mathrm{RC}$ beam within the whole structure. Figure 8 shows different types of RC beams in a typical plan and elevation layout of an 


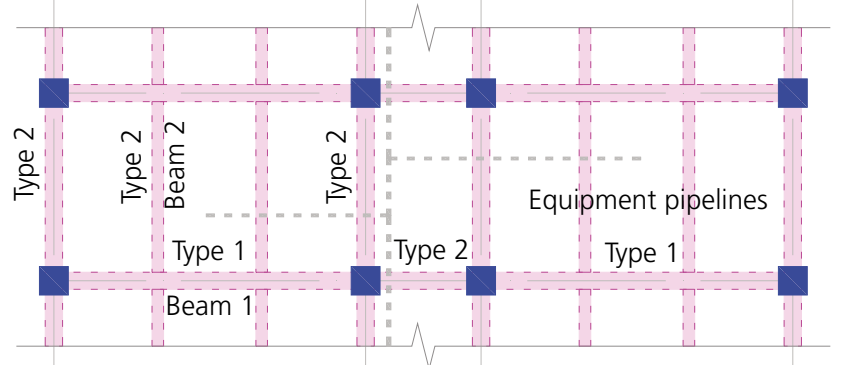

(a)

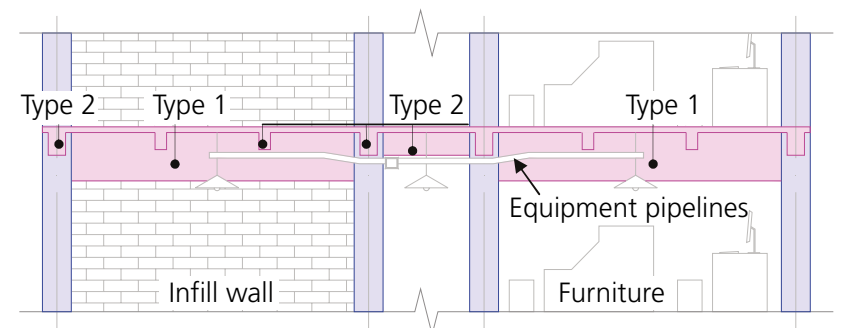

(b)

Figure 8. A typical RC structural layout: (a) plan; (b) elevation

RC building. Figure 9 presents the available BSP strengthening schemes for different types of RC beams.

As an under-reinforced beam performs differently for different tensile steel ratios, the following definition of lightly and moderately reinforced beams is adopted in the subsequent discussion. A lightly reinforced beam, whose tensile steel ratio is less than $1 / 3$ of the balance steel ratio $\left(\rho_{\mathrm{st}}<(1 / 3) \rho_{\mathrm{stb}}\right)$, fails in a ductile mode. In most cases, its flexural strength is less than $40 \%$ of that of the balanced reinforced beam; thus, it can be enhanced significantly by adding external reinforcement, with a small sacrifice in ductility. In contrast, a moderately reinforced beam, whose reinforced degree is greater than $2 / 3$ $\left(\rho_{\text {st }} / \rho_{\text {stb }}>2 / 3\right)$, fails in a brittle mode. Its flexural strength is usually more than $80 \%$ of that of the balanced reinforced beam; thus, adding external tensile reinforcement cannot

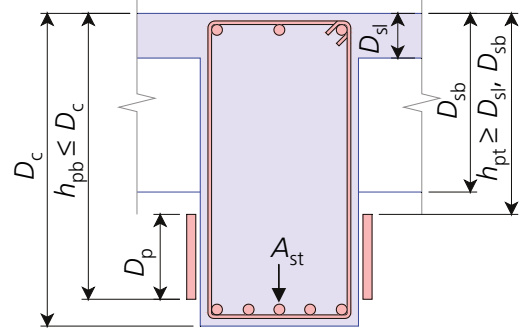

(a)

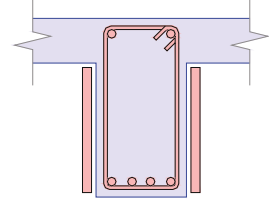

(b)

Figure 9. Strengthening strategies for RC beams of (a) type 1 and (b) type 2 increase its flexural strength significantly but can cause a very brittle failure with little ductility.

As shown in Figure 8, type 1 beams are usually main girders with a very large clear span. Large clear heights are typically not required because the space under these beams is usually occupied by infilled walls or furniture. However, the external loads imposed on these beams are usually of great magnitude, including those transferred from floor slabs, secondary beams and infilled walls. Furthermore, as the ductility capacity principle of 'strong column, weak beam' is usually required for main girders by design codes, a steel ratio of less than $2 / 3$ of the balance steel ratio $\left(\rho_{\mathrm{st}}<(2 / 3) \rho_{\mathrm{stb}}\right)$ is usually preferable. Therefore, type 1 beams are usually designed with a large beam depth, but are lightly reinforced to achieve significant flexural strength and ductility. Although the depth of the beam is great, there are limited areas on the side faces for use of the side-bolted steel plates, due to connections with secondary beams. When a load-bearing capacity greater than the original design is required, the strengthening technique of BSP beams with shallow steel plates is especially suitable for type 1 beams, as shown in Figure 9(a). The shallow steel plates serve as additional external tensile reinforcement, and increase the degree of reinforcement, thus enhancing the flexural strength. The main failure mode of type 1 beams strengthened with shallow steel plates is the yielding of the tensile reinforcement and the bolted plates.

The degree of strengthening of type 1 beams is governed by the difference between the current steel ratio and the preferred steel ratio $\left((2 / 3)\left(\rho_{\text {stb }}-\rho_{\text {st }}\right)\right)$. This is because, although thicker steel plates can always be chosen to achieve greater reinforcement, the required ductility capacity in the design code should always be guaranteed. The available area on the side faces is also a parameter controlling the strengthening effect. This is because the degree of partial interaction is limited by the available number of anchor bolts, which is mainly governed by the available side face area, as the minimum bolt spacing is strictly regulated in the design codes.

As shown in Figure 8, type 2 beams are usually secondary beams or main girders with a shorter beam span and are subjected to lighter external loads. For these beams, large clear heights below the beams are usually required for the installation of equipment, pipelines and ceilings. Therefore, type 2 beams are usually designed to be shallow with a modest beam depth, but are moderately reinforced with large tensile reinforcement $\left(A_{\mathrm{st}}\right)$. For type 2 beams, using deep steel plates can increase both their tensile and compressive reinforcement, and thus enhance their flexural strength without any notable reduction in ductility, as shown in Figure 9(b).

As the use of deep steel plates increases both the tensile and compressive reinforcement, the tensile steel ratio $\left(\rho_{\mathrm{st}}\right)$ is no longer an obstacle to the strengthening effect of type 2 beams. 
The available side face area becomes the key parameter, as it controls both the available plate depth and the maximum number of anchor bolts.

Lastly, buckling in the compressive region of the deep steel plates is the greatest potential risk for type 2 strengthened beams. It should be suppressed by taking appropriate measures, such as increasing the number of anchor bolts, or installing or welding steel angles to the compressive edge of the steel plates.

\section{Worked example}

\subsection{Current state of the structure requiring strengthening}

For brevity and illustration, let us assume that Figure 8(a) shows the plan layout of a prefabricated RC structure factory building, and that all beams are simply supported. The originally designed live load was $5 \mathrm{kN} / \mathrm{m}^{2}$, but this now needs to be increased to $12 \mathrm{kN} / \mathrm{m}^{2}$ as a result of a change in use. Therefore, proper retrofitting measures should be applied to the structure. For illustration, only the strengthening designs of a main girder and a secondary beam, labelled beam 1 and beam 2 in Figure 8(a), are discussed herein. Simplified models are shown in Figure 10, and the section details are given in Figure 11.

The originally designed loads before any change in use can be computed as

37. $F_{1}=219 \mathrm{kN} \mathrm{m} \quad q_{2}=32.8 \mathrm{kN} \mathrm{m}$

Thus, the originally designed moments on beams 1 and 2 are

38. $M_{\mathrm{d}, 1}=525.7 \mathrm{kNm} \quad M_{\mathrm{d}, 2}=147.6 \mathrm{kN} \mathrm{m}$

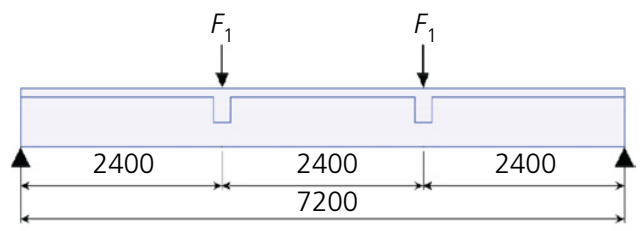

(a)

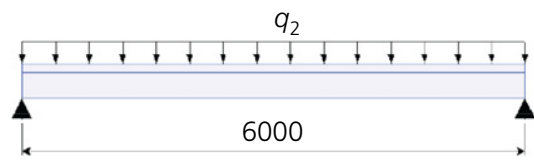

(b)

Figure 10. Simplified models for (a) beam 1 (a main girder) and (b) beam 2 (a secondary beam) (dimensions in $\mathrm{mm}$ )

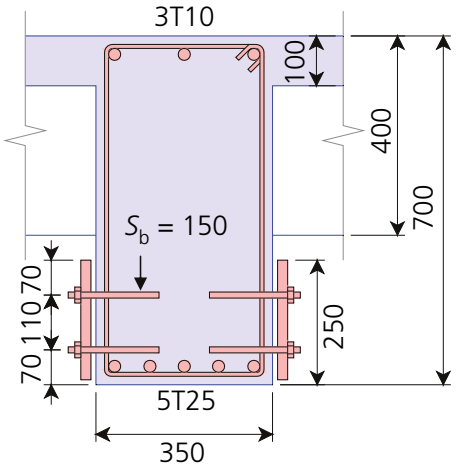

(a)

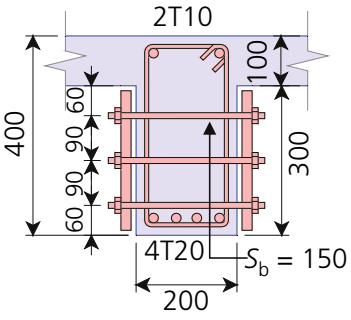

(b)
Figure 11. Strengthening details for (a) beam 1 and (b) beam 2 (dimensions in $\mathrm{mm}$ )

The designed material properties are

39. $f_{\text {ck }}=30 \mathrm{MPa} \quad f_{\mathrm{y}}=460 \mathrm{MPa} \quad E_{\mathrm{s}}=200 \mathrm{GPa}$

The section properties of beams 1 and 2, respectively, are

40.

$$
h_{0,1}=667 \mathrm{~mm} \quad A_{0,1}=232050 \mathrm{~mm} \quad A_{\mathrm{sc}, 1}=942 \mathrm{~mm}^{2}
$$$$
A_{\text {st }, 1}=2453 \mathrm{~mm}^{2} \quad \rho_{\mathrm{st}, 1}=1 \cdot 06 \%
$$

41.

$$
\begin{aligned}
h_{0,2} & =367 \mathrm{~mm} \quad A_{0,2}=72600 \mathrm{~mm} \quad A_{\mathrm{sc}, 2}=632 \mathrm{~mm}^{2} \\
A_{\mathrm{st}, 1} & =1256 \mathrm{~mm}^{2} \quad \rho_{\mathrm{st}, 2}=1.73 \%
\end{aligned}
$$

The original flexural strengths of beams 1 and 2 can be computed by using the design formulas in the Eurocodes (BSI, 2004) as

\section{2. $M_{\mathrm{uRC}, 1}=615 \cdot 2 \mathrm{kN} \mathrm{m} \quad M_{\mathrm{uRC}, 2}=166 \cdot 1 \mathrm{kN} \mathrm{m}$}

Therefore, the originally designed structure is safe before a change in use for bearing moments less than the flexural strengths, as follows

43. $M_{\mathrm{d}, 1}=525.7 \mathrm{kNm}<M_{\mathrm{uRC}, 1}=615.2 \mathrm{kN} \mathrm{m}$

44. $\quad M_{\mathrm{d}, 2}=147.6 \mathrm{kN} \mathrm{m}<M_{\mathrm{uRC}, 2}=166.1 \mathrm{kN} \mathrm{m}$

However, as the live load increases to $12 \mathrm{kN} / \mathrm{m}^{2}$ due to a change in use, the actual loads are

45. $\quad F_{1}^{\prime}=380 \cdot 3 \mathrm{kN} \mathrm{m} \quad q_{2}^{\prime}=59.7 \mathrm{kN} \mathrm{m}$ 
Thus, the design moments on beams 1 and 2 increase significantly, as follows

\section{6. $\quad M_{\mathrm{d}, 1}^{\prime}=912.8 \mathrm{kNm} \quad M_{\mathrm{d}, 2}^{\prime}=268.5 \mathrm{kNm}$}

Therefore, the original RC beams 1 and 2 are unsafe following a change in use, because the design moments are much greater than the flexural strengths, as follows

47. $M_{\mathrm{d}, 1}^{\prime}=912 \cdot 8 \mathrm{kNm} \gg M_{\mathrm{uRC}, 1}=615 \cdot 2 \mathrm{kN} \mathrm{m}$

48. $\quad M_{\mathrm{d}, 2}^{\prime}=268 \cdot 5 \mathrm{kN} \mathrm{m} \gg M_{\mathrm{uRC}, 2}=166 \cdot 1 \mathrm{kN} \mathrm{m}$

\subsection{Arrangement of steel plates}

As the top part of the side faces of beam 1 is occupied by the secondary beams, and only the bottom part is available for the installation of steel plates, a shallow plate depth of $D_{\mathrm{p}, 1}=$ $250 \mathrm{~mm}$ is chosen. On the other hand, considering the moderate steel ratio $\left(\rho_{\mathrm{st}, 2}=1 \cdot 73 \%\right)$ of beam 2 , the largest possible plate depth of $D_{\mathrm{p}, 2}=300 \mathrm{~mm}$ is chosen. A trial plate thickness of $t_{\mathrm{p}}=6 \mathrm{~mm}$ is also chosen for both beams, and can be adjusted accordingly where insufficient flexural strength is proved.

By taking the optimum strain and curvature factors $\alpha=0 \cdot 6$ and using Equations 17 and 18, the designed flexural strengths can be computed for beams 1 and 2, respectively, as

49.

$$
A_{1}=1.420 \times 10^{4} \quad B_{1}=-5.973 \times 10^{6}
$$

$C_{1}=5.380 \times 10^{8} \quad c_{1}=289 \mathrm{~mm}$

50. $\Rightarrow M_{\mathrm{uBSP}, 1}=1039.7 \mathrm{kN} \mathrm{m}$

51. $\left\{\begin{array}{l}\varepsilon_{\mathrm{sc}}=0.0031>\varepsilon_{\mathrm{y}}=0.002 \\ -\varepsilon_{\mathrm{pt}}=0.0011<\varepsilon_{\mathrm{yp}}=0.0017 \\ \varepsilon_{\mathrm{pb}}=0.0029>\varepsilon_{\mathrm{yp}}=0.0017\end{array}\right.$

$\Rightarrow$ Equations 17 and 18 are suitable

52.

$$
A_{2}=1.180 \times 10^{4} \quad B_{2}=-2 \cdot 181 \times 10^{6}
$$

$C_{2}=2.651 \times 10^{8} \quad c_{2}=199 \mathrm{~mm}$
53. $\Rightarrow M_{\mathrm{uBSP}, 2}=277.7 \mathrm{kN} \mathrm{m}$

54. $\quad\left\{\begin{array}{l}\varepsilon_{\mathrm{sc}}=0.0029>\varepsilon_{\mathrm{y}}=0.002 \\ \varepsilon_{\mathrm{pt}}=0.0010<\varepsilon_{\mathrm{yp}}=0.0017 \\ \varepsilon_{\mathrm{pb}}=0.0023>\varepsilon_{\mathrm{yp}}=0.0017 \\ \Rightarrow \text { Equations } 17 \text { and } 18 \text { are suitable }\end{array}\right.$

Thus, beams 1 and 2 are safe after a change in use, as the bearing moments are less than the flexural strengths, as follows

55. $\quad M_{\mathrm{d}, 1}^{\prime}=912.8 \mathrm{kNm}<M_{\mathrm{uBSP}, 1}=1039.7 \mathrm{kNm}$

56. $\quad M_{\mathrm{d}, 2}^{\prime}=268.5 \mathrm{kN} \mathrm{m}<M_{\mathrm{uBSP}, 2}=277.8 \mathrm{kN} \mathrm{m}$

Furthermore, it is evident from Equation 51 that the top edge of the shallow steel plates are inverse to our pre-set sign convention, which means that all sections of the shallow steel plates are subjected to a tension force.

\subsection{Arrangement of anchor bolts}

Anchor bolts of grade $5.8\left(f_{\mathrm{ub}}=500 \mathrm{MPa}, S_{\mathrm{by}}=1.5 \mathrm{~mm}\right)$ with a diameter of $12 \mathrm{~mm}$ can be chosen for this strengthening design. The yield shear force of an anchor bolt is

57. $R_{\text {by }}=0.5 \times 500 \times \frac{\pi \times 12^{2}}{4}=28.3 \mathrm{kN}$

Substituting Equation 57 and the geometry and material properties of the steel plates into Equation 22 gives the estimated number of anchor bolts as, respectively 58. $\begin{aligned} \frac{1}{4} n_{\mathrm{b}, 1} & =2.0 \times \frac{(1 / 1.15) \times 355 \times(700-450) \times 6}{(1 / 1.25) \times 28.3 \times 10^{3}} \\ & =41 \text { pieces }\end{aligned}$

59. $\frac{1}{4} n_{\mathrm{b}, 2}=2.0 \times \frac{(1 / 1 \cdot 15) \times 355 \times(400-100) \times 6}{(1 / 1.25) \times 28.3 \times 10^{3}}$ $=50$ pieces

Because the depth of the steel plates for beam 1 is $250 \mathrm{~mm}$, two rows of anchor bolts can be used, and the corresponding 
computed bolt spacing is

60. $S_{\mathrm{b}, 1}=\frac{7200 / 2}{41 / 2}=176 \mathrm{~mm}$

Of course, the computed bolt spacing is an approximate estimation, and two rows of bolts with a bolt spacing of $S_{\mathrm{b}, 1}=$ $150 \mathrm{~mm}$ is actually chosen for fabrication convenience; thus, the total number of bolts for beam 1 is

61. $n_{\mathrm{b}, 1}=2 \times 2 \times\left(\frac{7200}{150}+1\right)=196$ pieces

Because the depth of steel plates for beam 2 is $300 \mathrm{~mm}$, three rows of anchor bolts can be used, and the corresponding computed bolt spacing is

62. $S_{\mathrm{b}, 2}=\frac{7200 / 2}{50 / 3}=216 \mathrm{~mm}$

For fabrication convenience, three rows of bolts with a bolt spacing of $S_{\mathrm{b}, 2}=150 \mathrm{~mm}$ are actually chosen; thus, the total number of bolts for beam 2 is

63. $n_{\mathrm{b}, 2}=2 \times 3 \times\left(\frac{7200}{150}+1\right)=296$ pieces

The bolt spacing in the vertical direction can be arranged to correspond with the steel structure design codes, and the final strengthening layouts are shown in Figure 11.

\subsection{Verification of partial interaction}

The stiffnesses of the RC beams, the steel plates and the bolt connections, along with the corresponding stiffness ratios, are computed according to their geometry and material properties for beams 1 and 2 as, respectively

64. $\left\{\begin{array}{cc}(E A)_{\mathrm{p}, 1}=6.30 \times 10^{8} \mathrm{~N} & (E I)_{\mathrm{p}, 1}=3.28 \times 10^{12} \mathrm{~N} \mathrm{~mm}^{2} \\ (E A)_{\mathrm{c}, 1}=1.66 \times 10^{9} \mathrm{~N} & (E I)_{\mathrm{c}, 1}=9.04 \times 10^{13} \mathrm{~N} \mathrm{~mm}^{2} \\ \beta_{\mathrm{a}, 1}=\frac{6.30 \times 10^{8}}{1.66 \times 10^{9}}=0.38 & \beta_{\mathrm{p}, 1}=\frac{3.28 \times 10^{12}}{9.04 \times 10^{13}}=0.036\end{array}\right.$

65. $\left\{\begin{array}{cc}(E A)_{\mathrm{p}, 2}=7.56 \times 10^{8} \mathrm{~N} & (E I)_{\mathrm{p}, 2}=5.67 \times 10^{12} \mathrm{~N} \mathrm{~mm}^{2} \\ (E A)_{\mathrm{c}, 1}=6.91 \times 10^{9} \mathrm{~N} & (E I)_{\mathrm{c}, 2}=1.25 \times 10^{13} \mathrm{~N} \mathrm{~mm}^{2} \\ \beta_{\mathrm{a}, 2}=\frac{7.56 \times 10^{8}}{6.91 \times 10^{9}}=1.09 & \beta_{\mathrm{p}, 2}=\frac{5.67 \times 10^{12}}{1.25 \times 10^{13}}=0.454\end{array}\right.$
66. $K_{\mathrm{b}}=\frac{28.3 \times 10^{3}}{1.5}=18900 \mathrm{~N} / \mathrm{mm}$

67. $\left\{\begin{array}{l}k_{\mathrm{m}, 1}=2 \times \frac{18900}{150}=251 \mathrm{~N} / \mathrm{mm}^{2} \\ \beta_{\mathrm{m}, 1}=\frac{252}{9 \cdot 04 \times 10^{13}}=2.78 \times 10^{-12} \mathrm{~mm}^{-4}\end{array}\right.$

68. $\left\{\begin{array}{l}k_{\mathrm{m}, 2}=3 \times \frac{18900}{150}=378 \mathrm{~N} / \mathrm{mm}^{2} \\ \beta_{\mathrm{m}, 2}=\frac{378}{1.25 \times 10^{13}}=3.02 \times 10^{-11} \mathrm{~mm}^{-4}\end{array}\right.$

The parameters $p$ and $\xi_{\mathrm{p}}$, which are used for computation of the longitudinal slips and strain factors, can be computed for beams 1 and 2 as, respectively

69. $i_{\mathrm{c}, 1}=234 \mathrm{~mm} \quad i_{\mathrm{p}, 1}=72 \mathrm{~mm} \quad i_{\mathrm{cp}, 1}=225 \mathrm{~mm}$

70. $i_{\mathrm{c}, 2}=135 \mathrm{~mm}, \quad i_{\mathrm{p}, 2}=87 \mathrm{~mm}, \quad i_{\mathrm{cp}, 2}=50 \mathrm{~mm}$

71. $p_{1}=\sqrt{2.78 \times 10^{-12} \times\left(234^{2}+\frac{72^{2}}{0 \cdot 036}+\frac{225^{2}}{1+0.036}\right)}$

$=8.28 \times 10^{-4}$

72. $p_{1}=\sqrt{2.78 \times 10^{-12} \times\left(234^{2}+\frac{72^{2}}{0.036}+\frac{225^{2}}{1+0.036}\right)}$

$=8.28 \times 10^{-4}$

73. $L_{1}=7200 \mathrm{~mm} \quad L_{2}=6000 \mathrm{~mm}$

The peak loads for beams 1 and 2 can be derived from the ultimate flexural strength $\left(M_{\mathrm{u}}\right)$ as

74. $\quad F_{\mathrm{p}, 1}=\frac{1039 \cdot 7}{7 \cdot 2 / 3}=433 \cdot 1 \mathrm{kN}$ 
75. $q_{\mathrm{p}, 2}=\frac{277 \cdot 8}{6 \cdot 0^{2} / 8}=61 \cdot 7 \mathrm{kN} / \mathrm{m}$

Then, the maximum longitudinal slips $\left(S_{\mathrm{lc}, \text { max }}\right)$ at the peak loads can be obtained for beams 1 and 2 by using Equations 26 and 30 , respectively.

76. $\left.S_{\mathrm{lc}, \max , 1}\right|_{x=0}=\left.1.47 \mathrm{~mm} \quad S_{\mathrm{lc}, \max , 2}\right|_{x=0}=0.31 \mathrm{~mm}$

The maximum transverse slips $\left(S_{\mathrm{tr}, \max }\right)$ at the peak loads can also be obtained for beams 1 and 2, by using Equations 27 and 31 , respectively.

77. $\left.S_{\mathrm{tr}, \max , 1}\right|_{x=0}=\left.0.26 \mathrm{~mm} \quad S_{\mathrm{tr}, \text { max }, 2}\right|_{x=0}=1.11 \mathrm{~mm}$

78.

$$
\begin{aligned}
\xi_{\mathrm{S}, 2} & =25 L_{2}^{4} \beta_{\mathrm{m}, 2} \beta_{\mathrm{p}, 2}\left[21100 \beta_{\mathrm{p}, 2}+L^{4} \beta_{\mathrm{m}, 2}\left(\beta_{\mathrm{p}, 2}+1\right)\right] / C \\
& =6.90
\end{aligned}
$$

80.

$$
\begin{aligned}
D_{2}= & L^{8} \beta_{\mathrm{m}, 2}^{2}\left(\beta_{\mathrm{p}, 2}+1\right)\left(\beta_{\mathrm{p}, 2}+0 \cdot 65\right)+14600 \beta_{\mathrm{p}, 2} \\
& \times\left[L^{4} \beta_{\mathrm{m}, 2}\left(\beta_{\mathrm{p}, 2}+0 \cdot 8\right)-5500 \beta_{\mathrm{p}, 2}\right]=2 \cdot 75 \times 10^{9}
\end{aligned}
$$

Therefore, the resultant slips can be verified as follows

81.

$$
\begin{aligned}
& \left.\sqrt{S_{\mathrm{lc}, \text { max }, 1}^{2}+S_{\mathrm{tr}, \max 1}^{2}}\right|_{x=0}=\sqrt{1.47^{2}+0.26^{2}} \\
& =1.49 \mathrm{~mm}<S_{\mathrm{by}}=1.5 \mathrm{~mm}
\end{aligned}
$$

82.

$$
\begin{aligned}
& \left.\sqrt{S_{\mathrm{lc}, \text { max }, 2}^{2}+S_{\mathrm{tr}, \max , 2}^{2}}\right|_{x=0}=\sqrt{0.31^{2}+1.11^{2}} \\
& =1.55 \mathrm{~mm}<S_{\mathrm{by}}=1.5 \mathrm{~mm}
\end{aligned}
$$

The minimum strain and curvature factors $\left(\alpha_{\varepsilon, \min }\right.$ and $\left.\alpha_{\phi, \min }\right)$ can also be obtained for beams 1 and 2, based on Equations 28, 29, 32 and 33, respectively.

83.

$$
\alpha_{\varepsilon \min , 1}=0.61>\alpha=0 \cdot 6
$$

84. $\alpha_{\varepsilon \min , 2}=0 \cdot 67>\alpha=0 \cdot 6$

85. $\alpha_{\phi \min , 1}=0.55 \approx \alpha=0.6$

86. $\alpha_{\phi \min , 2}=0.56 \approx \alpha=0.6$

It is evident from Equations 81-86 that the maximum resultant slips and the minimum strain and curvature factors can satisfy the requirements, despite the minimum curvature factors being slightly less than the required limit. This strengthening arrangement will still be acceptable, owing to the conservation in the flexural strengths (see Equations 55 and 56) and the insensitive variation of the flexural strength as the strain and curvature factors when $\alpha_{\varepsilon \text {,min }}$ and $\alpha_{\phi \text {,min }}$ are greater than $0 \cdot 5$, as mentioned in the literature (Li, 2013). Of course, further computation shows that the actual flexural strengths of beams 1

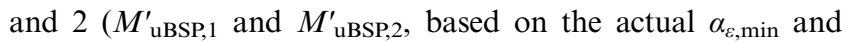
$\left.\alpha_{\phi, \text { min }}\right)$ are still conservative. For brevity, the computation is omitted, and the results are

87. $M_{\mathrm{d}, 1}^{\prime}=912.8 \mathrm{kNm}<M_{\mathrm{uBSP}, 1}^{\prime}=1037.1 \mathrm{kN} \mathrm{m}$

88. $M_{\mathrm{d}, 2}^{\prime}=268.5 \mathrm{kN} \mathrm{m}<M_{\mathrm{uBSP}, 2}^{\prime}=275.3 \mathrm{kN} \mathrm{m}$

\subsection{Discussion of the strengthening effectiveness and efficiency}

Taking $M_{\mathrm{d}}$ and $M^{\prime}{ }_{\mathrm{d}}$ to be the design moments before and after a change in use and $M_{\mathrm{uRC}}$ and $M_{\mathrm{uBSP}}^{\prime}$ to be the flexural strengths before and after strengthening, the corresponding design safety margins and enhancement percentages are tabulated in Table 2. The flexural strengths under a full-interaction assumption $\left(M_{\mathrm{uBSP}, \mathrm{FI}}\right)$, together with the corresponding design safety margins and enhancement percentages, are also computed for comparison.

The original flexural strengths of beams 1 and 2 are much lower than the required design moments after a change in use (the design safety margins are 0.67 and 0.62 , respectively), and thus both beams need to be strengthened (the required enhancements are $48 \%$ and $62 \%$, respectively). After appropriate strengthening is employed (see Figure 11), the actual enhancements are greater than the requirements $(69 \%>48 \%$ and $66 \%>62 \%$, respectively), and thus the structure is safe (the design safety margins are $1 \cdot 14$ and $1 \cdot 03$, respectively). 


\begin{tabular}{|c|c|c|c|}
\hline \multirow[b]{2}{*}{ Description } & \multirow[b]{2}{*}{ Expression } & \multicolumn{2}{|c|}{ Member type } \\
\hline & & Beam 1 & Beam 2 \\
\hline Design moment before a change in use & $M_{\mathrm{d}}$ & $525 \cdot 7(\mathrm{kN} \mathrm{m})$ & $147 \cdot 6(\mathrm{kN} \mathrm{m})$ \\
\hline Design moment after a change in use & $M_{d}^{\prime}$ & $912 \cdot 8(\mathrm{kN} \mathrm{m})$ & $268.5(\mathrm{kN} \mathrm{m})$ \\
\hline Flexural strength before strengthening & $M_{\mathrm{URC}}$ & $615 \cdot 2(\mathrm{kN} \mathrm{m})$ & $166 \cdot 1(\mathrm{kN} \mathrm{m})$ \\
\hline Flexural strength after strengthening & $M_{\text {UBSP }}^{\prime}$ & $1037 \cdot 1$ (kN m) & $275 \cdot 3(\mathrm{kN} \mathrm{m})$ \\
\hline Flexural strength under full interaction & $M_{\mathrm{uBSP}, \mathrm{FI}}$ & $1050 \cdot 0$ (kN m) & $288.0(\mathrm{kN} \mathrm{m})$ \\
\hline Design safety margin before a change in use & $M_{\mathrm{uRC}} / M_{\mathrm{d}}$ & $1 \cdot 17$ & $1 \cdot 13$ \\
\hline Design safety margin after a change in use & $M_{\mathrm{uRC}} / M_{\mathrm{d}}^{\prime}$ & $0 \cdot 67$ & $0 \cdot 62$ \\
\hline Design safety margin after strengthening & $M_{\mathrm{uBSP}}^{\prime} / M_{\mathrm{d}}^{\prime}$ & $1 \cdot 14$ & 1.03 \\
\hline Required enhancement & $\left(M_{\mathrm{d}}^{\prime} / M_{\mathrm{uRC}}\right)-1$ & $48 \%$ & $62 \%$ \\
\hline Actual enhancement & $\left(M_{\text {UBSP }}^{\prime} / M_{\text {uRC }}\right)-1$ & $69 \%$ & $66 \%$ \\
\hline Utmost enhancement under full interaction & $\left(M_{\mathrm{UBSP}, \mathrm{F}} / M_{\mathrm{URC}}\right)-1$ & $71 \%$ & $73 \%$ \\
\hline Strength loss due to partial interaction & $1-\left(M_{\mathrm{UBSP}}^{\prime} / M_{\mathrm{UBSP}, \mathrm{FI}}\right)$ & $1 \%$ & $4 \%$ \\
\hline Relative strengthening effect & $\left(M_{\mathrm{UBSP}}-M_{\mathrm{URC}}\right) /\left(M_{\mathrm{uBSP}, \mathrm{FI}}-M_{\mathrm{URC}}\right)$ & $97 \%$ & $90 \%$ \\
\hline
\end{tabular}

Table 2. Summary of the strengthening effects

It is also evident that the utmost enhancements when a full interaction assumption is employed are just slightly greater than the actual enhancements $(71 \%>69 \%$ and $73 \%>66 \%$ for beams 1 and 2, respectively). Strength losses due to partial interaction are negligible (only $1 \%$ and $4 \%$, respectively), and the actual strengthening capacity is greater than $90 \%$ of the full strengthening capacity, and thus is very satisfactory $(97 \%$ and $90 \%$, respectively). Therefore, the stiffness of the bolt connection is sufficient, and it is neither necessary nor economical to arrange too many anchor bolts in the strengthening of these two BSP beams.

\section{Conclusions}

In this paper, a new flexural design procedure has been proposed for strengthening of RC beams using the BSP technique. The modified flexural strength design formulas, which involve the influence of partial interaction, are presented. By adopting some optimum strain and curvature factors in the flexural capacity checking of BSP beams, the plate dimensions and the bolt arrangement can be determined. The main findings of this study can be summarised as follows.

The load capacity of BSP beams would be overestimated if an assumption of full interaction was employed in the calculation. On the other hand, more accurate results can be obtained by taking the partial interaction in the plate$\mathrm{RC}$ interface into account.

- The strain and curvature factors are used to quantify the longitudinal and transverse partial interaction. Only minor modification is needed for the conventional flexural strength formula of RC beams to cover the computation of the flexural strength of BSP beams, by employing the recommended strain and curvature factors.
- A strain or curvature factor of 0.6 can attain optimal enhancement with a reasonable number of anchor bolts; excessive connection is neither economical nor necessary.

- The recommended strain and curvature factors facilitate the strengthening design considerably, by dividing the design procedure into two parts: $(a)$ evaluation of the plate size using the modified flexural strength formulas; (b) evaluation of the required number of bolts by the plate size, followed by verification of the degree of partial interaction using the simplified formulas.

- The worked example shows the effectiveness and efficiency of the proposed design procedure in the strengthening design of RC beams using the BSP technique. This new design approach is not only easy to use but also offers greater accuracy than design methods using the assumption of full interaction.

\section{Acknowledgements}

The research described here received financial support from the Research Grants Council of the Hong Kong SAR (Project No. HKU7166/08E and HKU7151/10E) and the National Natural Science Foundation of China (Project No. 51408436).

\section{REFERENCES}

Adhikary BB, Mutsuyoshi H and Sano M (2000) Shear strengthening of reinforced concrete beams using steel plates bonded on beam web: experiments and analysis. Construction and Building Materials 14(5): 237-244.

BSI (2004) BS EN 1992-1-1:2004: Design of concrete structures: General rules and rules for buildings. BSI, London, UK. 
BSI (2005) BS EN 1993-1-8:2005: Design of steel structures: Design of joints. BSI, London, UK.

Buyukozturk O, Gunes O and Karaca E (2004) Progress on understanding debonding problems in reinforced concrete and steel members strengthened using FRP composites. Construction and Building Materials 18(1): 9-19.

Foley CM and Buckhouse ER (1999) Method to increase capacity and stiffness of reinforced concrete beams. Practice Periodical on Structural Design and Construction 4(1): $36-42$.

Hamoush SA and Ahmad SH (1990) Debonding of steel plate-strengthened concrete beams. Journal of Structural Engineering 116(2): 356-371.

Johnson RP and Molenstra N (1991) Partial shear connection in composite beams for buildings. Proceedings of the Institution of Civil Engineers 91(4): 679-704.

Li LZ (2013) New Partial Interaction Models for Bolted-sideplate Reinforced Concrete Beams. PhD thesis, University of Hong Kong, Hong Kong.

Li LZ, Lo SH and Su RKL (2013) Experimental study of moderately reinforced concrete beams strengthened with bolted-side steel plates. Advances in Structural Engineering 16(3): 499-516.

Lo SH, Li LZ and Su RKL (2014) Optimization of partial interaction in bolted side-plated reinforced concrete beams. Computers and Structures 131(15): 70-80.

Newmark NM, Siess CP and Viest IM (1951) Tests and analysis of composite beams with incomplete interaction. Proceedings of the Society for Experimental Stress Analysis 9(1): 75-92.

Nguyen NT, Oehlers DJ and Bradford MA (2001) An analytical model for reinforced concrete beams with bolted side plates accounting for longitudinal and transverse partial interaction. International Journal of Solids and Structures 38(38-39): 6985-6996.

Oehlers DJ, Nguyen NT, Ahmed M and Bradford MA (1997)

Transverse and longitudinal partial interaction in composite bolted side-plated reinforced-concrete beams. Structural Engineering and Mechanics 5(5): 553-563.

Roberts TM and Haji-Kazemi H (1989) Strengthening of under-reinforced concrete beams with mechanically attached steel plates. International Journal of Cement Composites and Lightweight Concrete 11(1): 21-27.

Siu WH (2009) Flexural Strengthening of Reinforced Concrete Beams by Bolted Side Plates. PhD thesis, University of Hong Kong, Hong Kong.

Siu WH and Su RKL (2009) Load-deformation prediction for eccentrically loaded bolt groups by a kinematic hardening approach. Journal of Constructional Steel Research 65(2): 436-442.

Siu WH and Su RKL (2010) Effects of plastic hinges on partial interaction behaviour of bolted side-plated beams. Journal of Constructional Steel Research 66(5): 622-633.

Siu WH and Su RKL (2011) Analysis of side-plated reinforced concrete beams with partial interaction. Computers and Concrete 8(1): 71-96.
Smith S, Bradford M and Oehlers D (1999a) Local buckling of side-plated reinforced-concrete beams. I: theoretical study. Journal of Structural Engineering 125(6): 622-634.

Smith S, Bradford M and Oehlers D (1999b) Local buckling of side-plated reinforced-concrete beams. II: experimental study. Journal of Structural Engineering 125(6): 635-643.

Smith S, Bradford M and Oehlers D (2000) Unilateral buckling of elastically restrained rectangular mild steel plates. Computational Mechanics 26(4): 317-324.

Souici A, Berthet JF, Li A and Rahal N (2013) Behaviour of both mechanically connected and bonded steel-concrete composite beams. Engineering Structures 49(1): 11-23.

Su RKL and Siu WH (2007) Nonlinear response of bolt groups under in-plane loading. Engineering Structures 29(4): 626-634.

Su RKL and Zhu Y (2005) Experimental and numerical studies of external steel plate strengthened reinforced concrete coupling beams. Engineering structures 27(10): 1537-1550.

Su R, Siu W and Smith S (2010) Effects of bolt-plate arrangements on steel plate strengthened reinforced concrete beams. Engineering Structures 32(6): 1769-1778.

Su RKL, Li LZ and Lo SH (2013) Shear transfer in bolted sideplated reinforced concrete beams. Engineering Structures 56(11): 1372-1383.

Su RKL, Li LZ and Lo SH (2014) Longitudinal partial interaction in bolted side-plated reinforced concrete beams. Advances in Structural Engineering 17(7): 921-936.

Subedi NK and Baglin PS (1998) External plate reinforcement for concrete beams. Journal of Structural Engineering 124(12): $1490-1495$. 